\title{
Multicriteria evaluation of biomass residues in Portugal to second generation bioethanol production
}

\author{
Afonso V. P. Fontes ${ }^{\mathrm{a}}$, Isabel Maria João ${ }^{\mathrm{a}, \mathrm{b} *}$ (D), João M. Silva ${ }^{\mathrm{a}, \mathrm{c}}$ \\ Instituto Politécnico de Lisboa, Instituto Superior de Engenharia de Lisboa, Lisboa, Portugal \\ bUniversidade de Lisboa, Instituto Superior Técnico, CEG-IST, Lisboa, Portugal \\ 'Universidade de Lisboa, Instituto Superior Técnico, CQE, Lisboa, Portugal \\ *ijoao@deq.isel.ipl.pt
}

\begin{abstract}
Paper aims: This study evaluates agricultural and forest residues in Portugal to select the best candidates to use in second generation bioethanol ( $2 \mathrm{G}$ bioethanol) production.

Originality: The growth in the significance and level of decisions in biomass resources to $2 \mathrm{G}$ bioethanol and the involved complexity clearly encourage a research strategy to identify and select the wastes according to a multiplicity of criteria.

Research method: To address the key research objective this research used a multicriteria decision analysis method, MACBETH, to structuring the values of concern and identifying the key criteria, to evaluating the main agricultural and forest waste with respect to each criterion, to weighting the criteria and analyzing the biomass residues overall attractiveness and exploring the model's results.

Main findings: As main findings of the study we found that Eucalyptus waste is the most promising forest residue to produce lignocellulosic bioethanol followed by Paulownia Tomentosa waste. The utilization of forest residues to the production of bioethanol in Portugal may represent in the future an important economic activity with huge environmental benefits.

Implications for theory and practice: The multicriteria approach addressed the research objectives and is simple to use with great potential for circular economy strategy issues. The step-by-step explanation of the model building makes the approach highly acceptable to other practitioners.
\end{abstract}

Keywords

2G bioethanol. Biomass residues. MCDA. MACBETH.

How to cite this article: Fontes, A. V. P., João, 1. M., \& Silva, J. M. (2021). Multicriteria evaluation of biomass residues in Portugal to second generation bioethanol production. Production, 31, e20210060. https://doi.org/10.1590/01036513.20210060 .

Received: May 31, 2021; Accepted: Aug. 30, 2021.

\section{Introduction}

Overcoming the problem of global warming and pollution due to fossil fuel consumption is imperative and one of the greatest challenges of our times. Increasing the global energy production from renewable sources by 2030 to combat climate change and minimize its impacts on populations around the world is vital, reason why European legislation established the goal of improving energy efficiency by 32.5\% until 2030 (Energy Efficiency Directive 2012/27/EU, recently amended to Directive (EU) 2018/2002) (Trotta, 2019). With this in mind, in accordance with the policies and the targets defined and approved internationally by different countries, it was decided to incorporate until 2030 between 20\% and 30\% of ethanol in gasoline (Jahid et al., 2018).

When ethanol is produced by alcoholic fermentation process, mediated by yeasts, filamentous fungi, or bacteria from simple sugars, namely pentoses, C5 (i.e., xylose), or hexoses, C6 (i.e., glucose), and it is not provided by oil refineries, it is called bioethanol (Rosa, 2006). Bioethanol has increasingly emerged on the market as the biofuel 
that will replace gasoline in the next years. Nowadays, it is considered the most produced biofuel worldwide and it also accounted for about 73\% of the 135.3 billion liters of biofuel produced in 2016 (Branco et al., 2018).

Bioethanol has been successfully integrated into the national fuel systems of some countries, in low mixtures with gasoline, without modifying the engine (Handler et al., 2016). The introduction of bioethanol in explosion engines has several benefits in relation to gasoline. On the one hand, this green fuel consists of $34.7 \%$ oxygen, which leads to an increase in combustion efficiency, by about 15\%, compared to gasoline, which does not have this element in its composition, resulting in lower emissions of nitrogen oxides, carbon monoxide (Sophanodorn et al., 2020) and PM particles (Domínguez et al., 2017). All these compounds are emitted by gasoline, and they have a harmful effect on the environment, because they contribute to the worsening of the phenomenon of acid rain and the contamination of groundwater (Sophanodorn et al., 2020). Bioethanol also has a high-octane number, which allows engines to operate at a higher compression rate (Branco et al., 2018) offering, for this reason, greater safety for the driver (Jahid et al., 2018). Moreover, this fuel can replace other additives, such as octane propellants, and it can also provide greater braking efficiency (Cutzu \& Bardi, 2017). It is considered an attractive substitute for premium engines (PMS), as it is completely biodegradable (Efeovbokhan et al., 2019) and the products which result from its incomplete oxidation, namely acetic acid, and acetaldehyde, are less toxic than other alcohol (Cutzu \& Bardi, 2017).

First generation bioethanol is currently the most produced biofuel, mainly based on the use of food crops and it constitutes a threat and a concern for the food chain and for biodiversity (Branco et al., 2018). In the face of the pressure around the food industry, second generation technologies have emerged, which use raw materials of non-food origin, to produce bioethanol, namely lignocellulosic biomass (LCB). The production of bioethanol from LCB increases the demand for this green fuel, as it makes it possible to obtain several by-products of high added value, such as ethanol vapor (used in the production of hydrogen, mainly in fuel cells), ethylene, ethylene glycol, glycol, acetaldehyde, ethyl acetate, acrylates, ethyl chloride, butane, propylene, butadiene, and ethane, which is considered a precursor to polyethylene, polypropylene, and polyvinyl chloride (Gonçalves et al., 2015). Also, carbon dioxide, which is the main secondary product of alcoholic fermentation, can be reused in the production of microbial biomass, in the manufacture of carbonated/soft drinks and in the production of syngas for example (Gonçalves et al., 2015).

In addition to the byproducts production advantages, the greatest benefit of second-generation bioethanol is the reuse of agricultural, forest and industrial wastes, offering an alternative to the utilization waste and the environmental impact resulting from its unsuitable destination (Song et al., 2020). Thus, it is more and more crucial to follow a circular economy strategy, a reason why bioeconomy and then the circular economy have gained political traction during the second decade of this century (Organisation for Economic Co-operation and Development, 2018).

The main motivation to perform this study is related to the mobilization of huge number of resources that currently may be considered wastes (i.e., forestry residues, agricultural residues) and gradually replacing the fossil fuel-based production with bio-based production to guarantee social, economic, and environmental benefits. The production of $2 \mathrm{G}$ bioethanol may help improving the rural economy and social benefits as it contributes to the creation of jobs since it is necessary to mobilize a lot of labor to collect cellulosic waste having in mind the production of $2 \mathrm{G}$ bioethanol. In addition, contributes to improve sustainability due to the reduction of greenhouse gas emissions, and role to regional development (Elemike et al., 2015). However, up till now the conversion of wastes to $2 \mathrm{G}$ bioethanol still presents some constraints, in particular the residues quantification along the food supply chain, the scarcity of data on its quality and level of homogeneity and the differences in the implementation of waste regulations in different countries (Prasoulas et al., 2020).

From the standpoint of Portugal, the main source of greenhouse gas emissions (GHG) is related to fossil fuel combustion in the energy sector with power plants, oil refineries, transport and industry being the main contributors (Monteiro et al., 2011). The climate in Portugal is prone to biomass production since it is a temperate climate mostly rainy in winter and with a warm summer (Peel et al., 2007). The distribution of land use in Portugal mainland is around 35\% forest, 32\% bushes and pastureland, 24\% agriculture, with the remaining urban area, inlet water and a productive land (Instituto da Conservação da Natureza e das Florestas, 2019). The waste forest residues in Portugal are mainly from landowners with only around $2.5 \%$ belonging to public bodies and forests correspond to approximately one third of the territory (Pinho, 2014). Agriculture is also very important for the Portuguese economy and around 360000 hectares of the land area is olive groves generating a high amount of biomass waste (Fonseca, 2020).

Ferreira et al. (2017) present one of the few recent studies discussing the current state and prospects for the biomass in Portugal. Currently in Portugal, there are some companies dedicated to the production of biodiesel FAME, mainly from used cooking oils (UCO) (Portugal, 2021) but regarding to bioethanol, its incorporation into 
gasoline has been ensured essentially by imported bioethanol (Portugal, 2021). However, given the potential of bioethanol as a business of the future, companies dedicated to its production are beginning to emerge (Saini et al., 2020) with forest residues, olive pomace, olive pruning and some solid urban residues, for the purpose of bioethanol production by a Portuguese company (Stex, 2020).

This work intends to make the evaluation of the various types of agricultural and forest waste in Portugal, in order to be used as a resource to produce $2 \mathrm{G}$ bioethanol. The selection of the various types of waste can be seen as a multicriteria problem, where different alternatives (i.e., different wastes) will be analyzed, according to a multiplicity of evaluation criteria, to select the most promising biomass residues. This is a key step in the process of waste selection. Provided the expected growth in the significance and rate of decisions being made in the biomass resources to bioenergy sector and the complexity of the systems being created there is a clear out request for multicriteria decision analysis (MCDA) methods to be applied.

MCDA covers a wide range of distinct methodologies and techniques (Figueira et al., 2005). The choice of a particular method is very dependent on the decision context and among some of the best well known MCDA methods are for example the analytical hierarchy process (AHP) and analytical network process (ANP) developed by Saaty (1987) or outranking methods as for example ELECTRE (Elimination Et Choix Traduisant la Realité - Elimination and Choice Expressing Reality) (Roy, 1968), (Vincke,1989) or PROMETHEE (Preference Ranking Organizations Method for Enrichement Evaluations) techniques) (Brans, 1982) among others. Also, Multi-attribute utility theory (MAUT) with the development of utility functions and scale constants aggregated into a single synthesis criterion (Keeney \& Raiffa, 1993) or MAVT where the multi attribute value theory is the appropriate option as MACBETH (measuring attractiveness by a categorical-based evaluation technique) that allow to measure differences of attractiveness between two options at a time against a multiplicity of criteria (Bana e Costa \& Vansnick, 1994), (Bana e Costa et al., 2011). MACBETH has proven to be an excellent interactive method to deal with problems where semantic judgements about the differences in attractivity of several stimuli will help to quantify their relative attractiveness (Bana e Costa et al., 1999, 2002). Ferreira et al. (2017) present a literature review on MACBETH of the last 20 years pointing out the usefulness of the method with applications in public and private decision-making contexts.

The main reasons that lead us to choose the MACBETH method is related to the theoretical fundamentals and versatility of the method. Also, the simplicity of the method was a key point as it requires only qualitative judgments about differences of attractiveness between two elements at a time to generate numerical scores for the alternatives in each criterion and to weight the criteria. The MACBETH approach allows the researchers to easily build an interval scale of preferences on a set of alternatives without forcing evaluators to produce direct numerical representations of their preferences and this was considered a strong reason for choosing the aforementioned method to evaluate biomass resources for bioethanol production.

The paper presents the main steps of building the multicriteria model to evaluate the potential of various forests and agricultural residues to produce $2 \mathrm{G}$ bioethanol. Section 2 presents the methodology with the background of MACBETH and the general steps to model building and analysis. In section 3 the biomass residues evaluation is performed based on the methodology depicted and the results presented. Section 4 presents the discussion and analysis of the results. Finally, the conclusions are presented with the main findings and implications for the practice.

\section{Methodology}

The main goal of this study is to analyze the potential of various forests and agricultural residues existing in Portugal with the main objective produce $2 \mathrm{G}$ bioethanol. In Portugal biomass waste, mostly finds conventional low values use with agricultural residues usually used as they are for animal feed or spread on fields (Bio-based Industries Consortium, 2018). As in relation to forest residues they usually go into energy and a lot can be done in Portugal to maximize the utilization of Biomass residues in the production of bioethanol. Second generation bioethanol production in Portugal is practically non-existent, but it can represent in the future an important economic activity and contribute to generate environmental benefits. The $2 \mathrm{G}$ bioethanol can be produced from the biomass residues, such as agricultural or forest wastes considerably increasing the value of a resource that is currently still seen as a waste. This is very advantageous because these feedstocks do not increase concerns related to food sustainability, also have a low and usually stable price, and do not demand for extra land. The lignocellulosic biomass is among these types of feedstocks comprising different types of biomasses such as agricultural residues (i.e., straw, corner, wheat, sugarcane, stover), forest materials (i.e., mainly wood materials) and energy crops (e.g., perennial grasses) (Zabed et al., 2016). 
In this context, the use of a multicriteria decision analysis method that allows the evaluation of the various types of biomass residues existing in Portugal is adequate due to the different fundamental points of view necessary to evaluate the distinct alternatives. The MACBETH method is the approach used to build the evaluation model and compare the different alternatives (i.e., Biomass wastes), according to the selected evaluation criteria.

\subsection{Background of MACBETH}

MACBETH consists of a value measurement procedure that, unlike other procedures like numeric direct rating, uses qualitative judgements of differences in attractivity to generate value scores for the alternatives. The approach relies on a pairwise comparison mode and uses seven qualitative categories of difference in attractiveness (i.e., no difference, very weak difference, weak difference, moderate difference, strong difference, very strong difference, and extreme difference). MACBETH derives the partial values for the alternatives within each evaluation criterion consistent with the set of judgments with the goal of quantifying the relative attractiveness of the alternatives on an interval scale within each evaluation criterion. The weight of the criteria can also be derived through the MACBETH procedure through a set of hypothetical reference options and the global value of the alternatives is obtained using an additive value function model, by calculating the weighted average value of each alternative on the criteria. MACBETH makes use of some mathematical programming techniques to test the consistencies and find recommendations to overcome the inconsistencies that may be present. For more information on the theoretical aspects of the MACBETH method see (Bana e Costa et al., 2012). The M-MACBETH software implements the MACBETH method (available at www.m-macbeth.com) and provides tools that allow complex evaluations involving both quantitative and qualitative criteria as well as interactive sensitivity and robustness analyses of alternatives' overall comparisons.

\subsection{Model building and analysis}

The model building and analysis tasks involve structuring, evaluation, and analysis of the results (Figure 1).

The process begins with the elicitation of the fundamental points of view that the research team considered to be the criteria by which the attractiveness of any potential alternative should be appraised.

Once the set of criteria (i.e. fundamental points of view) and the performance descriptors are defined $\left(x_{i}, i=1,2, \ldots, n\right)$, the next step consists in the evaluation of the criteria weights followed by the additive value function model where the performance profile of each alternative $x$ is represented by $\left(x_{1}, x_{2}, \ldots x_{n}\right)$ where $x_{i}$ corresponds to a certain level of $x_{i}$. The global value of the alternative $x$ is obtained through the additive value function model as:

$$
V\left(x_{1}, x_{2}, \ldots, x_{n}\right)=\sum_{i=1}^{n} k_{i} \times v_{i}\left(x_{i}\right)
$$

with $\sum_{i=1}^{n} k_{i}=1$ and $k_{i} \geq 0$, where $v_{i}$ is a cardinal value criterion function defined on the set of alternatives and quantifies the local attractiveness of the alternatives with respect to the fundamental points of view, and $v_{i}\left(\right.$ neutral $\left._{i}\right)=0$ and $v_{i}\left(\right.$ good $\left._{i}\right)=100$ where neutral $_{i}$ and good $_{i}$ are respectively the plausible good and neutral performance levels in the descriptor of the $i^{\text {th }}$ fundamental point of view.
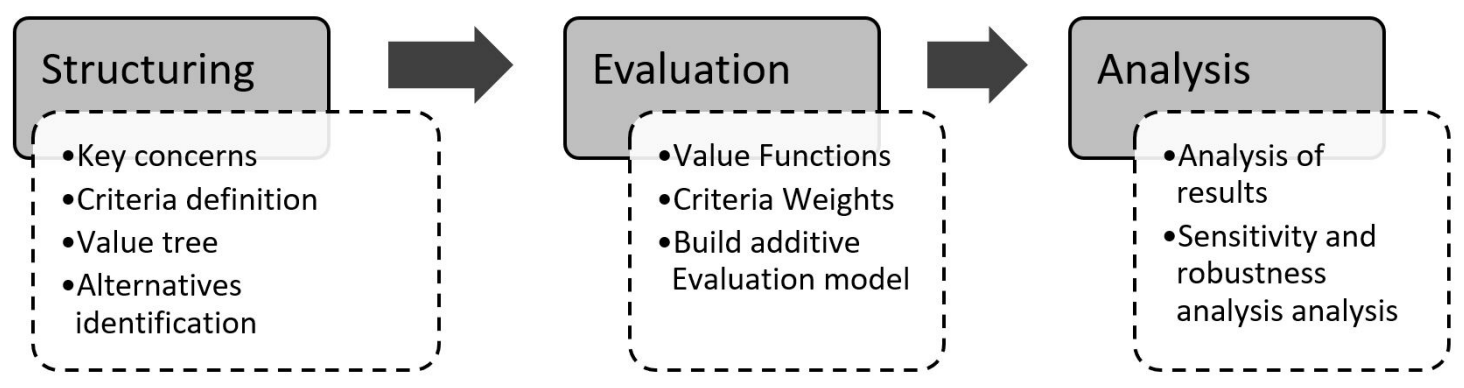

Figure 1. Model building and analysis tasks. 
The criteria weights $k_{i}, i=1,2, \ldots n$, (i.e., scaling constants) are determined with the assistance of MACBETH in the context of a simple additive aggregation model to harmonize the $[0,100]$ partial value scales of each criterion and perform the evaluation of the global attractivity of each alternative.

Once the additive evaluation model is built the alternatives can be evaluated and the interactive use of the MACBETH decision support system is extremely helpful to perform sensitivity and robustness analysis. Sensitivity analysis on a criterion weight allows the visualization of the extent by which the model's results would change as a result of changes made to the weight of a criterion.

The software's output window can be used interactively with any data input windows allowing to interactively analyze the sensitivity of the model's results to variations in judgements, performance, values, and weights. It is also possible to analyze the robustness of the model exploring the extent to which the conclusions can be drawn given incomplete, imprecise or uncertain information.

\section{Biomass residues evaluation}

The structuring step began with the identification of the key concerns that the research team considered to be relevant to appraise the distinct forest and agricultural residues to produce $2 \mathrm{G}$ bioethanol: the "Geographical Distribution of the Biomass Waste in Portugal", the "Biomass Waste Availability in Portugal", and the "Waste Utilization Capacity". Several levels of specification may be considered in the definition of the fundamental points of view (i.e., evaluation criteria) and it is useful to represent the evaluation criteria in a tree structure, as depicted in Figure 2.

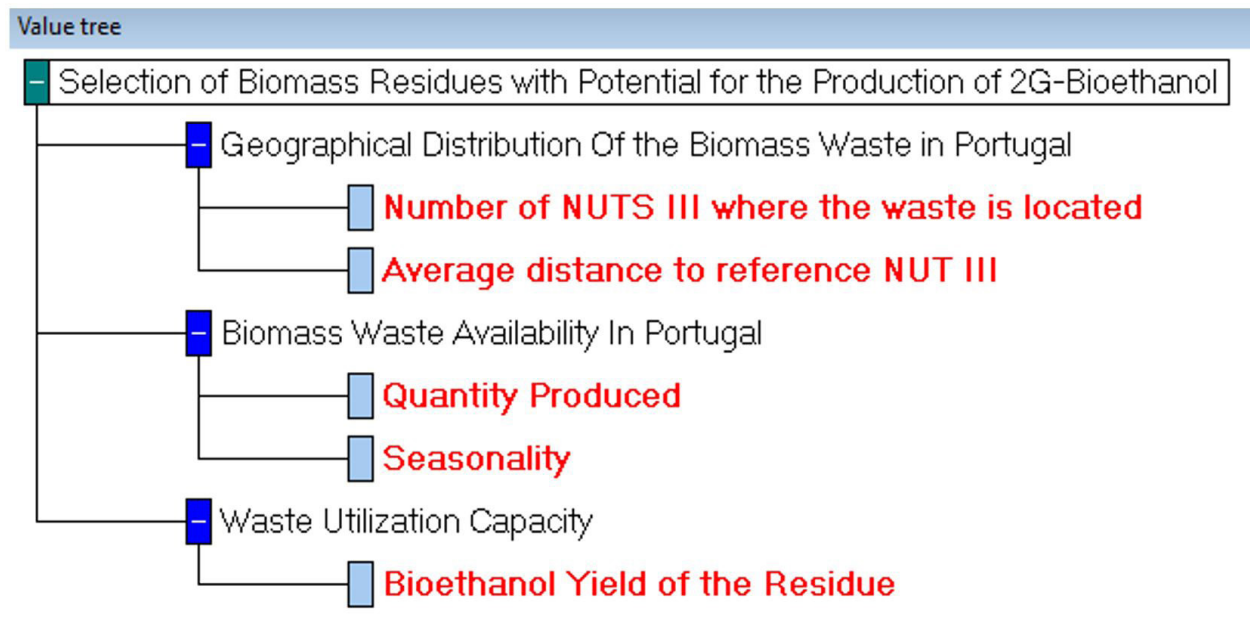

Figure 2. Value tree of the criteria for the selection of Biomass Residues.

The Key concern "Biomass Waste Availability" in Portugal was deployed in two main evaluation criteria: the "Quantity Produced" that is measured, thorough a quantitative descriptor of performance representing the total amount of biomass annually generated in the country and measured in kilotons (kt); and the evaluation criterion "Seasonality" with a quantitative descriptor of performance representing the waste availability throughout the year and measured in months.

The key concern "Geographical Distribution of the Biomass Waste in Portugal" was deployed in two evaluation criterion the "number of NUTS 111 where the waste is located" and the "average distance to the reference NUT III". NUTS is the acronym for Nomenclature of Units for Territorial Statistical purposes, that corresponds to a hierarchical system for dividing the territory into regions. At the top of the NUTS hierarchy is the National territory of the Member States of the European Union, with the coding structure broken down into three levels: NUTS 1, NUTS 11 and NUTS 111. In 2015, a new regional division came into force in Portugal - NUTS 2013 and in relation to the previous version - NUTS 2002 -, this translates into significant changes in the number and municipal composition of NUTS 111, which went from 30 to 25 territorial units, now referred to as 'administrative units' in accordance with the Commission Regulation (European Union, 2014) and represented in Figure 3. The concentration of each waste across the territory was assessed by determining the average distance from the 


\section{NUTS III}
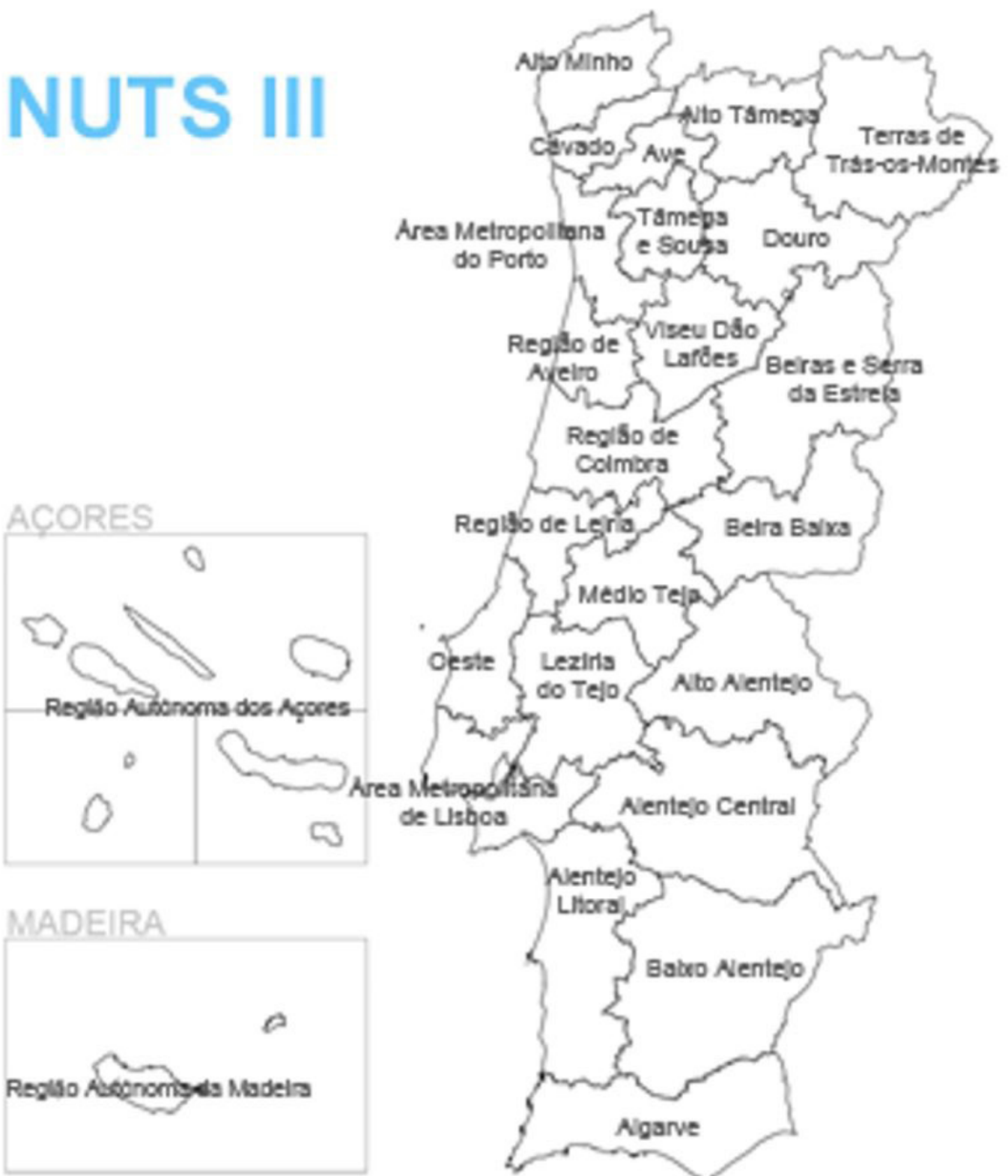

Figure 3. Municipalities in Portugal grouped into 25 NUTS 11 (Fundação Francisco Manuel dos Santos, 2021).

reference NUT 111. To define the criterion "average distance to the reference NUT III" the reference NUT III for each waste was the one where the largest amount of waste is generated. Thus, for each residue, after knowing which NUT 111 has the largest amount of waste produced, the distance in $\mathrm{km}$ of that NUT was determined from each of the remaining NUTS 111 where the residue exists and then the average of these distances was calculated. Note that the shorter the average distance, the more concentrated the waste is in the territory with less dispersion.

In relation to the "Waste Utilization Capacity" the selected evaluation criterion was the "Bioethanol Yield of the Residue" measured by the \% of Yield.

After the definition of the evaluation criteria and the descriptors of performance for each criterion the next step was the identification of the alternatives (i.e., the biomass residues) with potential to $2 \mathrm{G}$ bioethanol production. The biomass residues were selected according to their availability in Portugal and the possibility to be used to $2 \mathrm{G}$ bioethanol Production (i.e., considering the technologies already published to produce $2 \mathrm{G}$ 
bioethanol with the types of biomass residues identified). Regarding forest residues, the potential of Eucalyptus residues, Paulownia Tomentosa, pine, beech and bamboo was investigated. The agricultural residues studied were banana, pineapple, lemon, coffee, corn, wheat, barley, rice, soy, cassava, chestnut, and olive oil residues. In Portugal, there is no relevant cultivation of coffee, cassava, and soy, so these residues were excluded from the present study, which focuses on residues generated only in the national territory. However, it should be noted that coffee and soy residues can achieve high yields, 98\% (Burniol-Figols et al., 2016) and 96.2\% (Choi et al., 2015) respectively, which in coffee and soy producing countries should not be discarded. Cassava residues, on the other hand, can present a yield of up to 57.2\%, (Efeovbokhan et al., 2019) which makes them less interesting for this purpose. The potential of tobacco and hemp residues was also analyzed.

A total of 16 biomass residues was screened and inserted into the M-MACBETH software along with their performances with respect to each evaluation criterion. The biomass residues selected were the Eucalyptus, hemp, beech, pine, banana, tobacco, bamboo, wheat, pineapple, corn, barley, rice, Paulownia, Lemon, chestnut, and olive oil.

The evaluation step started with the creation of a value scale for each of the criteria. For example, for the criterion "Bioethanol Yield of the Residue" the cardinal value function was constructed for its quantitative descriptor Yield in \%. The value function serves to translate the performance of each biomass residue into partial value scores of the biomass residue in terms of the criterion and so indicating the attractiveness of the biomass residue relative to each other. The research team considered five levels of Yield in \% and selected 65\% as neutral level and the 95\% as good level and these reference levels would later serve as the scale anchors and assigned the arbitrary values 0 and 100, respectively. The research team judged qualitatively the difference in attractiveness between each two levels of performance through the choice of one of the seven MACBETH semantic categories and the answers is represented in Figure 4 along with the MACBETH scale.

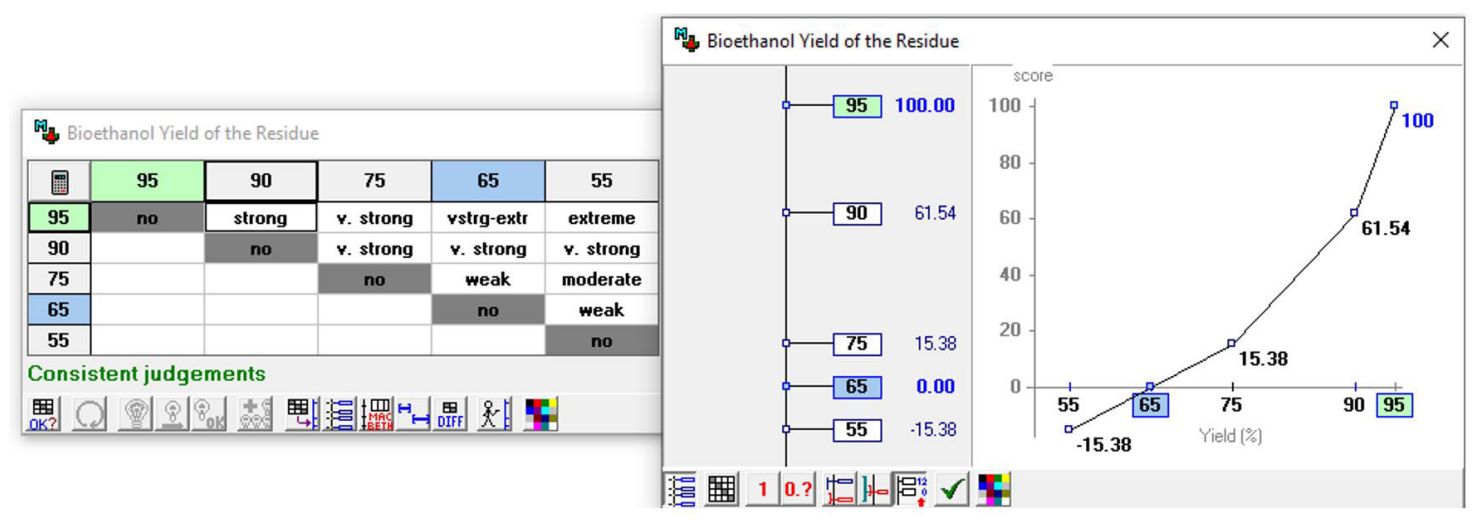

Figure 4. Matrix of semantic judgements and value function for bioethanol yield of residue.

The shape of the value function shows that there is much more value added to Yield in the upper area of the yield function than in the lower area of the Yield function and this shape totally reflects the research team judgement system of value. The Yield of the biomass residues was obtained through a detailed literature search considering the various types of technologies that can be used to produce $2 \mathrm{G}$ bioethanol for each type of biomass waste and selecting for each one the highest yield published. Table 1 presents the performances of the residues according to the criterion "Bioethanol yield of the residue" and the partial values obtained for all the residues in the respective criterion.

The Biomass residues partial values are obtained according to the criterion "Bioethanol yield of the residue" value function represented in Figure 4.

The process of value function creation for the remaining criteria was repeated according to a similar procedure and the value functions for the criteria that represent the key concern "Geographical Distribution of the Biomass Waste in Portugal" are represented in Figure 5.

For the criteria that represent the key concern "Biomass Waste availability in Portugal" the value functions were also built as depicted in Figure 6.

The criteria weights were then determined following the MACBETH weighting procedure. As already mentioned, the weights are scale constants to convert partial values of the alternatives, into global value units. 


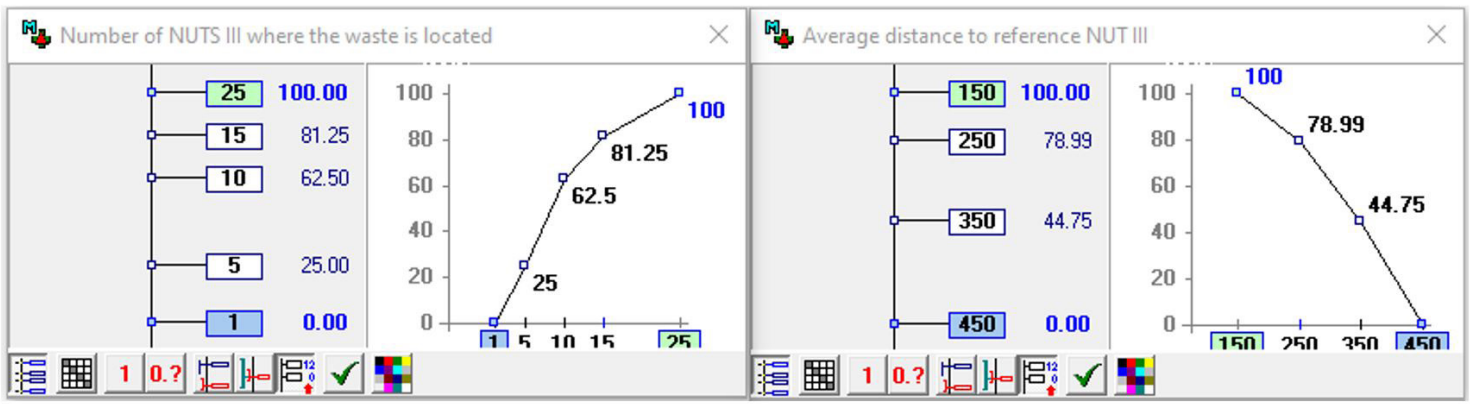

Figure 5. Value Functions for the criteria Number of NUTS 111 where the waste is located and Average distance to reference NUT 111.

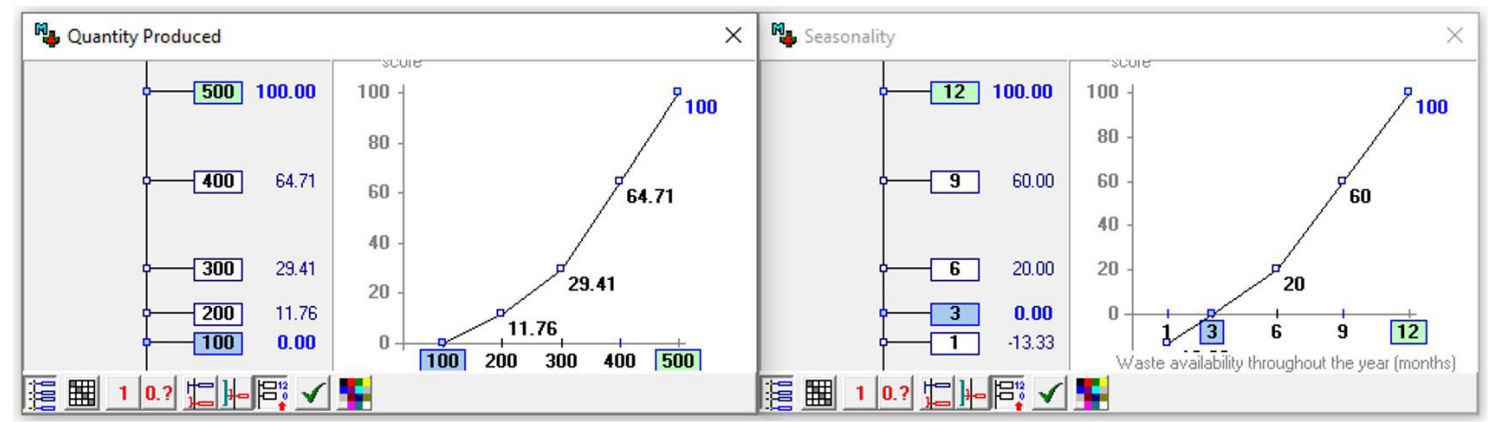

Figure 6. Value Functions for the criteria Quantity Produced and Seasonality.

Table 1. Biomass residue performance according to bioethanol Yield.

\begin{tabular}{ccc}
\hline Waste & Yield & Reference \\
\hline Eucalyptus & 99 & Romaní et al. (2019) \\
Hemp & 89 & Kuglarz et al. (2016) \\
Beech & 68 & Katsimpouras et al. (2017) \\
Pine & 21 & Dong et al. (2018) \\
Banana & 91 & Palacios et al. (2019) \\
Tobacco & 97 & Sarbishei et al. (2020) \\
Bamboo & 93 & Yuan et al. (2017) \\
Wheat & 95 & Hasanly et al. (2018) \\
Pineapple & 33 & Jahid et al. (2018) \\
Corn & 6 & Braide et al. (2016) \\
Barley & 97 & Lara-Serrano et al. (2018) \\
Rice & 84 & Jin et al. (2020) \\
Paulownia & 100 & Domínguez et al. (2017) \\
Lemon & 86 & John et al. (2020) \\
Chestnut & 97 & Morales et al. (2018) \\
Olive oil & 20 & Battista et al. (2016) \\
\hline
\end{tabular}

Figure 7 presents the weighting references where the [All lower] represents a hypothetical alternative with the performance in all criteria equal to the performances of the neutral level in these criteria and the other are alternatives whose performance in the respective criterion is equal to its upper reference and whose performance in the remaining criteria are equal to their neutral level.

The MACBETH weighting matrix is represented in Figure 8 and corresponds to the weighting procedure made by the research team. Looking at the hypothetical alternative where all the criteria are in the neutral level [All lower] if only one criterion could be changed to the reference level good the research team agreed that it should be the quantity. The second was Yield, and then the average distance to reference NUT IIl, the number of NUTS 111 and finally the Seasonality. Looking at the last column it is also possible to conclude that the research team judged the improvement of neutral to good in the criterion quantity as "very strong", and the improvement of the Yield from neutral to good as "strong to very strong" and so on. For more information related to the MACBETH weighting procedure, see (Bana e Costa \& Vansnick, 1999). 


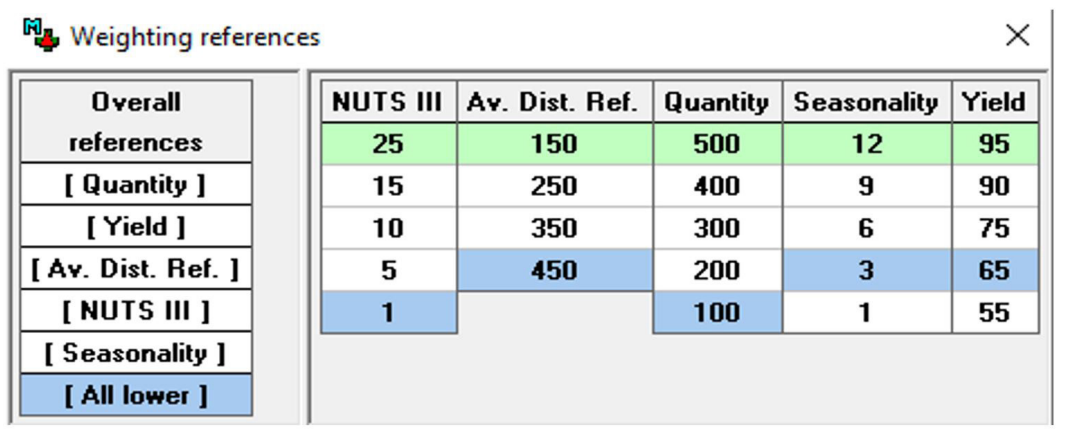

Figure 7. Weighting references.

\begin{tabular}{|c|c|c|c|c|c|c|}
\hline 圈 & [ Quantity ] & [ Yield ] & [ Av. Dist. Ref. ] & [ NUTS III ] & [ Seasonality ] & [ All lower ] \\
\hline [ Quantity ] & $\overline{\text { no }}$ & very weak & mod-strg & strong & strg-vstr & ४. strong \\
\hline [ Yield ] & & no & moderate & mod-strg & strong & strg-vstr \\
\hline [ Av. Dist. Ref. ] & & & no & very weak & very weak & weak \\
\hline [ NUTS III ] & & & & no & very weak & very weak \\
\hline [ Seasonality ] & & & & & no & very weak \\
\hline [ All lower ] & & & & & & no \\
\hline
\end{tabular}

Figure 8. MACBETH weighting matrix.

After providing all the judgements as depicted in Figure 8, it was possible to determine the criteria weights according to Figure 9.

A table with the global values of the Biomass residues was created (Figure 10) allowing the research group to see the results of the model and the scores of the options.

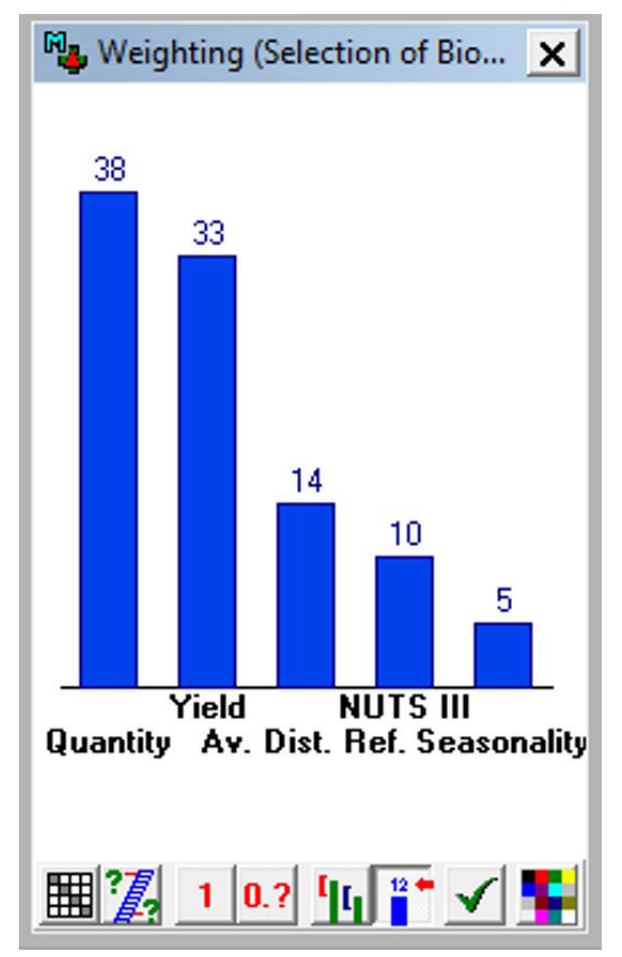

Figure 9. Histogram with the weight of the criteria. 


\begin{tabular}{|c|c|c|c|c|c|c|}
\hline \multicolumn{7}{|c|}{ The of scores } \\
\hline Options & Overall & NUTS III & Av. Dist. Ref. & Quantity & Seasonality & Yield \\
\hline [ all upper ] & 100.00 & 100.00 & 100.00 & 100.00 & 100.00 & 100.00 \\
\hline Eucaliptus & 95.77 & 100.00 & 89.71 & 65.95 & 100.00 & 130.77 \\
\hline Pawlonia & 63.96 & 62.50 & 81.93 & -11.72 & 100.00 & 138.46 \\
\hline Corn & 63.72 & 100.00 & 49.20 & 202.69 & -6.67 & -90.48 \\
\hline Chestnut & 55.14 & 100.00 & 76.94 & -8.88 & -6.67 & 115.38 \\
\hline Tobacco & 53.19 & 62.50 & 95.17 & -11.75 & 0.00 & 115.38 \\
\hline Wheat & 53.16 & 96.25 & 49.20 & 10.47 & -6.67 & 100.00 \\
\hline Barley & 50.53 & 96.25 & 49.20 & -8.94 & -13.33 & 115.38 \\
\hline Banana & 42.91 & 6.25 & 131.52 & -10.45 & 100.00 & 69.23 \\
\hline Bamboo & 40.94 & 6.25 & 105.25 & -8.37 & 6.67 & 86.15 \\
\hline Rice & 35.44 & 81.25 & 98.11 & 1.41 & -13.33 & 41.54 \\
\hline Hemp & 26.65 & 12.50 & 70.77 & -11.75 & 13.33 & 58.46 \\
\hline Lemon & 25.74 & 100.00 & -9.85 & -10.79 & 100.00 & 49.14 \\
\hline Beech & 24.00 & 83.13 & 96.85 & -11.69 & 100.00 & 4.77 \\
\hline Pine & 13.31 & 98.13 & 89.71 & 22.44 & 100.00 & -68.44 \\
\hline Olive Oil & 9.42 & 96.25 & 49.20 & 40.14 & 13.33 & -69.73 \\
\hline Pineapple & 2.72 & 0.00 & 131.52 & -11.72 & 100.00 & -49.22 \\
\hline [ all lower ] & 0.00 & 0.00 & 0.00 & 0.00 & 0.00 & 0.00 \\
\hline \multicolumn{2}{|c|}{ Weights } & 0.1000 & 0.1400 & 0.3800 & 0.0500 & 0.3300 \\
\hline
\end{tabular}

Figure 10. Table of scores for the evaluation of Biomass Residues.

\section{Discussion}

Observing Figure 10 it is possible to conclude that Eucalyptus waste is the most promising forest residue to produce lignocellulosic bioethanol with a high score. It is estimated that, throughout the year, in Portugal, around 403500 tons of Eucalyptus dry residues are generated (Bio-based Industries Consortium, 2018). Furthermore, these residues can obtain a maximum yield of 99\% (Romaní et al., 2019) and they can also be found in all NUTS 111 (Instituto Nacional de Estatística, 2019). However, they have a high average distance from the reference NUT 111 (Leiria, Região de Leiria): 199 km.

Another very promising type of waste, but still, not as much as Eucalyptus waste, is Paulownia Tomentosa waste with the second highest score. Although it is possible to achieve yields of 100\% with these residues (Domínguez et al., 2017) and knowing that they are available throughout the year, it is estimated that only between 150 and 300 tons of this type of waste are generated (Abreu et al., 2020). Moreover, Paulownia Tomentosa residues are only found in 10 NUTS 111 (Instituto Nacional de Estatística, 2019) and they have an average distance to the reference NUT 111 (Castelo-Branco, Beira-Baixa) even greater than the average distance of Eucalyptus residues: $236 \mathrm{~km}$.

Pine residues, on the other hand, fell short of expectations as can be concluded by the low score achieved by this type of residue. Although they are available throughout the year and they can be found in 24 NUTS 111 (Instituto Nacional de Estatística, 2019), this type of waste only provides a maximum yield of 20.5\% (Dong et al., 2018). Despite presenting about the same average distance to the reference NUT 111 (Leiria, Leiria Region) as Eucalyptus residues $(199 \mathrm{~km})$ and with about 260500 tons of this waste are produced per year (Bio-based Industries Consortium, 2018), this is not enough to produce $2 \mathrm{G}$ bioethanol on a large scale.

In turn, beech residues make it possible to obtain maximum yield values slightly higher (68.1\%) (Katsimpouras et al., 2017) than those of pine residues, but still, much lower than the yield values of Eucalyptus residues and of Paulownia Tomentosa residues. It is estimated that only 617 tons of this waste are produced per year. Although they are only found in the North and Center of the country which corresponds to 16 NUTS 111 (Abreu, 2021). Beech residues have a better score than Pine and they can also be obtained throughout the year, and they also present an average distance from the reference NUT 111 (Braga, Cávado) smaller (165 km) and so they are more concentrated in the territory than the previous waste.

Bamboo residues have a better global score when compared to beech and pine wastes because these residues are those that are the most concentrated in the territory, as they have the lowest average distance to the reference NUT 111 (Vidigueira, Baixo Alentejo) $(125 \mathrm{~km})$. It is estimated that about 28800 tons of bamboo are produced (Bambuparque, 2021), only in 2 NUTS 111 and only for 4 months a year (between May and August). However, they can reach a maximum yield of 92.3\% (Yuan et al., 2017), which means that, even though there are no large quantities of this waste dispersed throughout the country they reach a high score due to the yield that this type of residue can achieve. Even though bamboo does not have a very high score it is advised that this 
type of residue will be the subject of further investigation in future works, if there is an increase in bamboo production in Portugal.

Regarding agricultural residues, it was possible to note that residues from cereals, such as corn, wheat, and barley, are very promising to produce $2 \mathrm{G}$ bioethanol as we can see by the global score of these type of agricultural biomass residues. In Portugal, these residues are widely dispersed throughout the territory, and they are produced in large quantities. However, they have a high average distance $(337 \mathrm{~km})$ to the reference NUT 111 (Beja, Baixo Alentejo). Indeed, corn residues are estimated at 791000 tons (Bio-based Industries Consortium, 2018) and they can be found in all NUTS 111 (Instituto Nacional de Estatística, 2019). Wheat residues are estimated at 189000 tons (Bio-based Industries Consortium, 2018) and they can be found at 23 NUTS 111 (Instituto Nacional de Estatística, 2019). At last, barley residues are estimated at 24000 tons (Bio-based Industries Consortium, 2018) and they can be found in 23 NUTS 11l, too (Instituto Nacional de Estatística, 2019). Additionally, the harvest of these wastes occurs in the summer months. Thus, corn residues are collected in August and September, wheat residues in June and July, and barley residues only in September. Concerning the maximum yield in bioethanol, while wheat and barley waste present appreciable values, respectively 95\% (Hasanly et al., 2018) and 97\% (Lara-Serrano et al., 2018), corn residues present a very low value, about 6.17\%. (Braide et al., 2016). The large quantities produced, when compared to the rest of agricultural wastes just referred, and the number of NUTS 111 where they can be found makes the global score of this type of waste higher than the others, which quantities have a much lower expression. However, the corn will only make sense in the future by investigating technologies that can improve the corn yield.

In turn, rice residues, which are present in 15 NUTS 111 (Instituto Nacional de Estatística, 2019) are also produced in considerable quantities, about 112000 tons (Bio-based Industries Consortium, 2018), and their harvest occurs in September. These residues were not considered as promising as the residues of the remaining cereals. In fact, despite presenting an average distance to the reference NUT 111 (Santarém, Lezíria do Tejo) lower $(159 \mathrm{~km})$ than the residues of the remaining cereals, these residues present a maximum yield of $83.5 \%$ (Jin et al., 2020), therefore lower than the values of the wheat and barley residues. These are one of the reasons why these last agricultural residues score better than the rice.

Tobacco residues have a greater potential to produce $2 \mathrm{G}$ bioethanol when compared with hemp residues. Indeed, while tobacco residues can achieve a yield of up to 97\% (Sarbishei et al., 2020) and they are present in 10 NUTS 111 (Instituto Nacional de Estatística, 2019), hemp residues, at most, can achieve a yield of 89\% (Kuglarz et al., 2016) and they are only found in 3 NUTS 111 (Instituto Nacional de Estatística, 2019). Despite being present in less NUTS 111 than tobacco residues, the truth is that hemp residues have a greater average distance $(274 \mathrm{~km})$ to the reference NUT 111 (Grândola, Alentejo Litoral) than the average distance $(173 \mathrm{Km})$ NUT 111 of reference (Portalegre, Alto Alentejo) of tobacco residues. In terms of the number of residues generated, tobacco residues show better results (90 tons) (Food and Agriculture Organization of the United Nations, 2019), although these are not much better than those from hemp residues (59.64 tons) (Abreu, 2021) because both have very low values. Regarding seasonality, hemp residues are available between April and August, while tobacco residues are only available between June and August. All these differences were taken into consideration in the development of the multicriteria model reason why tobacco scores better than hemp.

Regarding fruit residues, it is estimated that 11136 tons of banana residues are generated (Food and Agriculture Organization of the United Nations, 2019) in the archipelagos of Madeira and the Azores (Instituto Nacional de Estatística, 2019), 351 tons of pineapple residues (Food and Agriculture Organization of the United Nations, 2017) only in the Azores archipelago (Instituto Nacional de Estatística, 2019). Also, 8225 tons of lemon residues (Food and Agriculture Organization of the United Nations, 2019) and 24526 tons of chestnut residues (Gírio, 2018) distributed throughout the national territory (Instituto Nacional de Estatística, 2019). For chestnut residues the average distance to the reference NUT 111 (Vila Real, Douro) is $256 \mathrm{~km}$ and that for lemon residues the average distance to the reference NUT 111 (Faro, Algarve) is $472 \mathrm{~km}$, presenting the worst average distance to the reference NUT 111 in the territory when compared to the rest of residues studied in this work. In terms of seasonality, while banana, pineapple and lemon residues can be obtained throughout the year, chestnut residues can only be collected in October and November. Finally, regarding the maximum bioethanol yield, banana residues can reach 91\% (Palacios et al., 2019), pineapple residues 33\% (Jahid et al., 2018), lemon residues 85.97\% (John et al., 2020) and chestnut residues the value of 97\% (Morales et al., 2018) reason why the chestnut residue has a partial score related to yield very high. Among the fruits studied, chestnut residues were considered the most promising, not only due to their high yield, but also since they are more concentrated in the territory.

Concerning olive oil residues, although it is estimated that about 330390 tons of residue are produced (Gírio, 2018) and they can be found in 23 NUTS 111 (Instituto Nacional de Estatística, 2019), but these residues 
do not allow to reach high yield values (maximum 19.66\%) (Battista et al., 2016) and they present a distance average to NUT 111 of reference (Beja, Baixo Alentejo) of $337 \mathrm{Km}$ which penalizes the residue along with the issue of seasonality because they can only be collected between October and February. All these reasons make the olive oil residue one with the lower global score.

\section{Conclusions}

According to the multicriteria assessment carried out, the residues found to have the greatest potential where Eucalyptus waste, followed by Paulownia Tomentosa waste. Some agricultural wastes are very promising, such as wheat or barley due to their high yield and number of NUTS 111 where the waste is located. Corn, despite having a much more attractive quantity available have huge limitations in relation to the yield. More studies are necessary to develop technologies that allow greater efficiency of this biomass residue to produce $2 \mathrm{G}$ bioethanol. The biomass residues that are at the bottom of the list in terms of global score according to the multicriteria model built are the pineapple at the bottom, followed by the olive oil and the pine.

The originality of the study is based in its contribution to unique insights regarding the evaluation and selection of biomass residues in Portugal to $2 \mathrm{G}$ bioethanol production. The better understanding of the potentialities of the different agricultural and forest residues according to different type of criteria is a plus and will give decision makers a better perception of the Portuguese biomass residues to produce $2 \mathrm{G}$ bioethanol whose actual production in Portugal is mainly nonexistent.

The MACBETH method was very helpful in the evaluation and selection of the residues considered promising for the large-scale production of lignocellulosic $2 \mathrm{G}$ bioethanol in Portugal and to better understand the ones that were currently considered inappropriate for this purpose. The alternatives studied (i.e., biomass residues) were evaluated against a multiplicity of criteria that helped to differentiate among the alternatives and select the most relevant biomass wastes according to the developed model and based on the researchers' preferences. MACBETH method is simple to use and very helpful to provide researchers with a step-by-step decision process, putting the researchers' systems of values in the first place and helping to develop a model for the decision making in the evaluation and selection of biomass wastes to the production of $2 \mathrm{G}$ bioethanol in Portugal.

Some practical implications of the study are related to MCDA method selected for fulfil the objective of this work. The selection of a suitable decision-making method is a critical part of the process and MACBETH method and the decision support software M-MACBETH proved to be very useful and suitable for carrying out the biomass residues multicriteria evaluation. The lessons learnt of the biomass residues evaluation in the Portuguese context will be helpful for future research and for practitioners. The decision making in circular economy and circularity issues to save resources is crucial for a sustainable world reason why the evaluation of alternatives that can be valued is a vital issue.

\section{References}

Abreu, M. J. (2021). A cultura do Canhamo. Portugal: Direção Regional da Agricultura e Pescas do Norte, Ministério da Agricultura, Mar, Ambiente e Ordenamento do Território. Retrieved in 2021, April 3, from http://www.drapn.min-agricultura.pt/drapn/conteudos/ producaoagricola/ACulturadoCanhamo.pdf

Abreu, M., Reis, A., Moura, P., Fernando, A. L., Luís, A., Quental, L., Patinha, P., \& Gírio, F. (2020). Evaluation of the potential of biomass to energy in Portugal: conclusions from the CONVERTE Project. Energies, 13(4), 937. http://dx.doi.org/10.3390/en 13040937.

Bambuparque. (2021). Retrieved in 2021, April 3, from https://bambuparque.pt/

Bana e Costa, C. A., \& Vansnick, J.-C. (1994). MACBETH: an interactive path towards the construction of cardinal value. International Transactions in Operational Research, 1(4), 489-500. http://dx.doi.org/10.1016/0969-6016(94)90010-8.

Bana e Costa, C. A., \& Vansnick, J.-C. (1999). The MACBETH approach: basic ideas, software, and an application. In N. Meskens \& M. Roubens (Eds.), Advances in decision analysis (Mathematical Modelling: Theory and Applications, No. 4). Dordrecht: Springer. http:// dx.doi.org/10.1007/978-94-017-0647-6_9.

Bana e Costa, C. A., Corrêa, E. C., de Corte, J.-M., \& Vansnick, J.-C. (2002). Facilitating bid evaluation in public call for tenders: a socio-technical approach. Omega, 30(3), 227-242. http://dx.doi.org/10.1016/S0305-0483(02)00029-4.

Bana e Costa, C. A., de Corte, J.-M., \& Vansnick, J.-C. (2011). MACBETH (Measuring Attractiveness by a Categorical Based Evaluation Technique). In J. J. Cochran, L. A. Cox Junior, P. Keskinocak, J. P. Kharoufeh \& J. C. Smith (Eds.), Wiley Encyclopedia of Operations Research and Management Science (pp. 2945-2950). New York: John Wiley \& Sons. http://dx.doi.org/10.1002/9780470400531. eorms0970.

Bana e Costa, C. A., de Corte, J.-M., \& Vansnick, J.-C. (2012). MACBETH. International Journal of Information Technology \& Decision Making, 11(2), 359-387. http://dx.doi.org/10.1142/S0219622012400068.

Bana e Costa, C. A., Ensslin, L., Cornêa, É. C., \& Vansnick, J.-C. (1999). Decision support systems in action: Integrated application in a multicriteria decision aid process. European Journal of Operational Research, 113(2), 315-335. http://dx.doi.org/10.1016/S03772217(98)00219-7. 
Battista, F., Mancini, G., Ruggeri, B., \& Fino, D. (2016). Selection of the best pretreatment for hydrogen and bioethanol production from olive oil waste products. Renewable Energy, 88, 401-407. http://dx.doi.org/10.1016/j.renene.2015.11.055.

Bio-based Industries Consortium - BIC. (2018). Mapping the potential of Portugal for the bio-based industry. Brussels. Retrieved in 2021, April 3, from https://www.apren.pt/contents/publicationsothers/mapping-the-potential-of-portugal-for-the-bio-base-industry.pdf

Braide, W., Kanu, l. A., Oranusi, U. S., \& Adeleye, S. A. (2016). Production of Bioethanol from agriculture waste. Journal of Fundamental and Applied Sciences, 8(2), 372-386. http://dx.doi.org/10.4314/jfas.v8i2.14.

Branco, R. H. R., Serafim, L. S., \& Xavier, A. M. R. B. (2018). Second generation bioethanol production: on the use of pulp and paper industry wastes as feedstock. Fermentation, 5(1), 4. http://dx.doi.org/10.3390/fermentation5010004.

Brans, J. P. (1982). L' Ingénierie de la décision: elaboration d'instrument d'aide à la décision: méthode PROMETHEE. In R. Nadeu \& M. Landry (Eds.), L'aide à la décision: nature, instruments et perspectives d'avenir. Québec: Les Presses de l'Université Laval.

Burniol-Figols, A., Cenian, K., Skiadas, l. V., \& Gavala, H. N. (2016). Integration of chlorogenic acid recovery and bioethanol production from spent coffee grounds. Biochemical Engineering Journal, 116, 54-64. http://dx.doi.org/10.1016/j.bej.2016.04.025.

Choi, S., Kim, Y. G., Jung, J. K., \& Bae, H.-J. (2015). Soybean waste (okara) as a valorization biomass for the bioethanol production. Energy, 93(Part 2), 1742-1747. http://dx.doi.org/10.1016/j.energy.2015.09.093.

Cutzu, R., \& Bardi, L. (2017). Production of bioethanol from agricultural wastes using residual thermal energy of a cogeneration plant in the distillation phase. Fermentation, 3(2), 24. http://dx.doi.org/10.3390/fermentation3020024.

Domínguez, E., Romaní, A., Domingues, L., \& Garrote, G. (2017). Evaluation of strategies for second generation bioethanol production from fast growing biomass Paulownia within a biorefinery scheme. Applied Energy, 187, 777-789. http://dx.doi.org/10.1016/j. apenergy.2016.11.114.

Dong, C., Wang, Y., Zhang, H., \& Leu, S.-Y. (2018). Feasibility of high concentration cellulosic bioethanol production from undetoxified whole Monterey pine slurry. Bioresource Technology, 250, 102-109. http://dx.doi.org/10.1016/j.biortech.2017.11.029. PMid:29161568.

Efeovbokhan, V. E., Egwari, L., Alagbe, E. E., Adeyemi, J. T., \& Taiwo, O. S. (2019). Production of bioethanol from hybrid cassava pulp and peel using microbial and acid hydrolysis. BioResources, 14(2), 2596-2609. Retrieved in 2021, April 3, from https://bioresources. cnr.ncsu.edu/resources/production-of-bioethanol-from-hybrid-cassava-pulp-and-peel-using-microbial-and-acid-hydrolysis/

Elemike, E. E., Oseghale, O. C., \& Okoye, A. C. (2015). Utilization of cellulosic cassava waste for bio-ethanol production. Journal of Environmental Chemical Engineering, 3(4, Part A), 2797-2800. http://dx.doi.org/10.1016/j.jece.2015.10.021.

European Union. (2014, August 13). Commission Regulation (EU) No. 868/2014 of 8 August 2014 amending the annexes to Regulation (EC) No. 1059/2003 of the European Parliament and of the Council on the establishment of a common classification of territorial units for statistics (NUTS). Official Journal of the European Union. Retrieved in 2021, August 17, from https://eur-lex.europa.eu/ legal-content/EN/TXT/?uri=CELEX:32014R0868

Ferreira, S., Monteiro, E., Brito, P., \& Vilarinho, C. (2017). Biomass resources in Portugal: current status and prospects. Renewable \& Sustainable Energy Reviews, 78, 1221-1235. http://dx.doi.org/10.1016/j.rser.2017.03.140.

Figueira, J. É., Greco, S., \& Ehrogott, M. (2005). Multiple criteria decision analysis: state of the art surveys. New York: Springer. http:// dx.doi.org/10.1007/b100605

Fonseca, J. E. (2020). Portuguese tech institute to produce advanced biofuels from tree-pruning-waste. Retrieved in 2021, April 3, from https://www.euractiv.com/section/agriculture-food/news/gerardo-portuguese-tech-institute-to-produce-advanced-biofuelswith-tree-pruning-waste/

Food and Agriculture Organization of the United Nations - FAO. (2017). Statistics. Retrieved in 2021, April 3, from http://www.fao. org/faostat/en/\#data/QC

Food and Agriculture Organization of the United Nations - FAO. (2019). Statistics. Retrieved in 2021, April 3, from http://www.fao. org/faostat/en/\#data/QC

Fundação Francisco Manuel dos Santos. PORDATA. (2021). What are NUTS? Retrieved in 2021, April 3, from https://www.pordata.pt/ en/What+are+NUTS

Gírio, F. (2018). Contributos para uma visão estratégica do uso da biomassa para aplicações energéticas. In Ciclo de Conferências do Pinhal Interior. Sertã, Portugal: SerQ - Centro de Inovação e Competências da Floresta. Retrieved in 2021, April 3, from https:// repositorio.lneg.pt/bitstream/10400.9/3160/1/Conferencia_Serta_Maio2018.pdf

Gonçalves, F. A., Silvino dos Santos, E., \& Ribeiro de Macedo, G. (2015). Use of cultivars of low cost, agroindustrial and urban waste in the production of cellulosic ethanol in Brazil: a proposal to utilization of microdistillery. Renewable \& Sustainable Energy Reviews, 50, 1287-1303. http://dx.doi.org/10.1016/j.rser.2015.05.047.

Handler, R. M., Shonnard, D. R., Griffing, E. M., Lai, A., \& Palou-Rivera, l. (2016). Life cycle assessments of ethanol production via gas fermentation: anticipated greenhouse gas emissions for cellulosic and waste gas feedstocks. Industrial \& Engineering Chemistry Research, 55(12), 3253-3261. http://dx.doi.org/10.1021/acs.iecr.5b03215.

Hasanly, A., Talkhoncheh, M. K., \& Alavijeh, M. K. (2018). Techno-economic assessment of bioethanol production from wheat straw: a case study of Iran. Clean Technologies and Environmental Policy, 20(2), 357-377. http://dx.doi.org/10.1007/s10098-017-1476-0.

Instituto da Conservação da Natureza e das Florestas - ICNF. (2019). IFN6 - 6 Inventário Florestal Nacional: principais resultados: relatório sumário. Retrieved in 2021, April 3, from https://www.fc.up.pt/pessoas/mccunha/Silvicultura/Aulas/estatisticas/IFN6Principais-resultados-Jun2019.pdf

Instituto Nacional de Estatística - INE. (2019). Estatísticas agrícolas - 2018. Retrieved in 2021, April 3, from https://www.ine.pt/xurl/ $\mathrm{pub} / 358629204$

Jahid, M., Gupta, A., \& Sharma, D. K. (2018). Production of bioethanol from fruit wastes (banana, papaya, pineapple and mango peels) under milder conditions. Journal of Bioprocessing \& Biotechniques, 8(3), 1000327. http://dx.doi.org/10.4172/2155-9821.1000327.

Jin, X., Song, J., \& Liu, G.-Q. (2020). Bioethanol production from rice straw through an enzymatic route mediated by enzymes developed in-house from Aspergillus fumigatus. Energy, 190, 116395. http://dx.doi.org/10.1016/j.energy.2019.116395. 
John, 1., Pola, J., Thanabalan, M., \& Appusamy, A. (2020). Bioethanol production from musambi peel by acid catalyzed steam pretreatment and enzymatic saccharification: optimization of delignification using taguchi design. Waste and Biomass Valorization, 11(6), 26312643. http://dx.doi.org/10.1007/s12649-018-00565-x.

Katsimpouras, C., Kalogiannis, K. G., Kalogianni, A., Lappas, A. A., \& Topakas, E. (2017). Production of high concentrated cellulosic ethanol by acetone/water oxidized pretreated beech wood. Biotechnology for Biofuels, 10(1), 54. http://dx.doi.org/10.1186/s13068017-0737-9. PMid:28265300.

Keeney, R. L., \& Raiffa, H. (1993). Decisions with multiple objectives. preferences and value trade-offs. Cambridge: Cambridge University Press. http://dx.doi.org/10.1017/CB09781139174084.

Kuglarz, M., Alvarado-Morales, M., Karakashev, D., \& Angelidaki, 1. (2016). Integrated production of cellulosic bioethanol and succinic acid from industrial hemp in a biorefinery concept. Bioresource Technology, 200, 639-647. http://dx.doi.org/10.1016/j. biortech.2015.10.081. PMid:26551652.

Lara-Serrano, M., Sáez Angulo, F., Negro, M. J., Morales-delaRosa, S., Campos-Martin, J. M., \& Fierro, J. L. G. (2018). Second-generation bioethanol production combining simultaneous fermentation and saccharification of lL-Pretreated Barley Straw. ACS Sustainable Chemistry \& Engineering, 6(5), 7086-7095. http://dx.doi.org/10.1021/acssuschemeng.8b00953.

Monteiro, E., Mantha, V., \& Rouboa, A. (2011). Prospective application of farm cattle manure for bioenergy production in Portugal. Renewable Energy, 36(2), 627-631. http://dx.doi.org/10.1016/j.renene.2010.08.035.

Morales, A., Gullón, B., Dávila, 1., Eibes, G., Labidi, J., \& Gullón, P. (2018). Optimization of alkaline pretreatment for the co-production of biopolymer lignin and bioethanol from chestnut shells following a biorefinery approach. Industrial Crops and Products, 124, 582-592. http://dx.doi.org/10.1016/j.indcrop.2018.08.032.

Organisation for Economic Co-operation and Development - OECD. (2018). Working party on biotechnology, nanotechnology and converging technologies realising the circular bioeconomy. Directorate for Science, Technology and Innovation Committee for Scientific and Technological Policy. Retrieved in 2021, April 3, from https://www.oecd.org/officialdocuments/publicdisplaydocume ntpdf/?cote=DST1/STP/BNCT(2017)7/FINAL\&docLanguage=En

Palacios, A. S., llyina, A., Ramos-González, R., Aguilar, C. N., Martínez-Hernández, J. L., Segura-Ceniceros, E. P., González, M. L. C., Aguilar, M., Ballesteros, M., Oliva, J. M. \& Ruiz, H. A. (2019). Ethanol production from banana peels at high pretreated substrate loading: comparison of two operational strategies. Biomass Conversion and Biorefinery. https://doi.org/10.1007/s13399-019-00562-7

Peel, M. C., Finlayson, B. L., \& McMahon, T. A. (2007). Updated world map of the Köppen-Geiger climate classification. Hydrology and Earth System Sciences, 11(5), 1633-1644. http://dx.doi.org/10.5194/hess-11-1633-2007.

Pinho, J. (2014). Forest planning in Portugal. In F. Reboredo (Eds.), Forest context and policies in portugal, world forests (Vol. 19, pp. 155-183). Switzerland: Springer International Publishing. http://dx.doi.org/10.1007/978-3-319-08455-8_6.

Portugal, Direção Geral de Energia e Geologia - DGEG. (2021). Áreas sectoriais-energia-energias renováveis e sustentabilidade. Retrieved in 2021, April 3, from https://www.dgeg.gov.pt/pt/areas-setoriais/energia/energias-renovaveis-e-sustentabilidade/

Prasoulas, G., Gentikis, A., Konti, A., Kalantzi, S., Kekos, D., \& Mamma, D. (2020). Bioethanol production from food waste applying the multienzyme system produced on-site by Fusarium oxysporum F3 and mixed microbial cultures. Fermentation, 6(2), 39. http:// dx.doi.org/10.3390/fermentation6020039.

Romaní, A., Larramendi, A., Yáñez, R., Cancela, Á., Sánchez, Á., Teixeira, J. A., \& Domingues, L. (2019). Valorization of Eucalyptus nitens bark by organosolv pretreatment for the production of advanced biofuels. Industrial Crops and Products, 132, 327-335. http:/l dx.doi.org/10.1016/j.indcrop.2019.02.040.

Rosa, M. F. (2006). Situação actual dos biocombustíveis e perspectivas futuras. Gazeta de Física, 29(1-2), 42-47. Retrieved in 2021, April 3, from https://www.spf.pt/magazines/GFIS/76/article/477/pdf

Roy, B. (1968). Classement et choix en presence de points de vue multiples. Revue Française d'informatique et de Recherche Opérationnelle, 2(6), 57-75. Retrieved in 2021, April 3, from http://www.numdam.org/article/RO_1968_2_1_57_0.pdf

Saaty, T. L. (1987). The analytic hierarchy process: what it is and how it is used. Mathematical Modelling, 9(3-5), 161-176. http://dx.doi. org/10.1016/0270-0255(87)90473-8.

Saini, S., Chutani, P., Kumar, P., \& Sharma, K. K. (2020). Development of an eco-friendly deinking process for the production of bioethanol using diverse hazardous paper wastes. Renewable Energy, 146, 2362-2373. http://dx.doi.org/10.1016/j.renene.2019.08.087.

Sarbishei, S., Goshadrou, A., \& Hatamipour, M. S. (2020). Mild sodium hydroxide pretreatment of tobacco product waste to enable efficient bioethanol production by separate hydrolysis and fermentation. Biomass Conversion and Biorefinery. http://dx.doi. org/10.1007/s13399-020-00644-X.

Song, Y., Lee, Y. G., Cho, E. J., \& Bae, H.-J. (2020). Production of xylose, xylulose, xylitol, and bioethanol from waste bamboo using hydrogen peroxide-acetic acid pretreatment. Fuel, 278, 118247. http://dx.doi.org/10.1016/j.fuel.2020.118247.

Sophanodorn, K., Unpaprom, Y., Whangchai, K., Homdoung, N., Dussadee, N., \& Ramaraj, R. (2020). Environmental management and valorization of cultivated tobacco stalks by combined pretreatment for potential bioethanol production. Biomass Conversion and Biorefinery. https://doi.org/10.1007/s13399-020-00992-8.

Stex. (2020). Smart technologies, by environment xperts. Retrieved in 2021, April 3, from https://www.stex.pt/

Trotta, G. (2019). Assessing energy efficiency improvements, energy dependence, and $\mathrm{CO}_{2}$ emissions in the European Union using a decomposition method Energy Efficiency. Energy Efficiency, 12(7), 1873-1890. http://dx.doi.org/10.1007/s12053-019-09818-7.

Vincke, P. H. (1989). L'aide multicritère à la dècision. Bruxelles: Éditions de l'Université de Bruxelles.

Yuan, Z., Wen, Y., Kapu, N. S., Beatson, R. \& Martinez, D. M. (2017). A biorefinery scheme to fractionate bamboo into high-grade dissolving pulp and ethanol. Biotechnology for Biofuels, 10, 38. https://doi.org/10.1186/s13068-017-0723-2.

Zabed, H., Sahu, J. N., Suely, A., Boyce, A. N. \& Faruq, G. (2016). Bioethanol production from renewable sources: Current perspectives and technological progress. Renewable and Sustainable Energy Reviews, 66, 751-774. https://doi.org/10.1016/j.rser.2016.08.038. 